\title{
USING COMPUTER ASSISTED INSTRUCTION \\ IN AN ESL LANGUAGE PROGRAM
}

Judy Leidy

Anne Merkel
Ann Burke

Marlin Howard

\section{INTRODUCTION}

Most arguments against computer assisted instruction in any language program center around the complexity of what is being taught. Language is indeed very complex, but there are areas of language which can be taught, and taught well, by a computer with the memory capacity of PLATO, a CAI system which will be described below. These areas which are the discrete, objectively testable areas of language, include grammar, spelling, vocabulary, and even the skills of speed reading, reading strategies, and writing organization. These areas can take up hours of instruction time which might be better used if directed toward those subtle areas of language involving synhesis, which can only be taught by a human being.

In using computer assisted instruction (CAI) at the Indiana University Center for English Language Training, we have found that PLATO can be an extremely useful and motivating supplement to classroum instruction. Indeed, it has been discovered that using PLATO for drill and practice has given us some advantages unobtainable in the language classroom or even in the customary language lab. Two major advantages are the instant feedback to the student and the individualization of the learning situation.

The computer, being a machine which lacks the sense of passing time, is far more patient than the teacher. It presents opportunities for the students to practice specific points over and over. Even in a relatively small class of ten to fifteen students, it is rare for a single student to be able to test his understanding of a single point more than once or twice.

The computer moves at the student's own pace. There is no pressure on the slow plodding student to hurry, while the faster student may move quickly through a lesson without the boredom and frustration of waiting for slower classmates to respond. The quick but overconfident student is brought in touch with reality, as the machine will not continue until the student responds with the required response.

This individualization may extend into the lessons themselves: in some lessons, branching ensures that students who understand the material go directly through the lesson, while those who have difficulty are routed through additional explanation and practice.

Considering the advantage of immediate feedback, unlike the teacher, CAI lessons are incapable of ignoring a mistake or a lack of response. If an answer is incorrect, the computer says so, and refuses to move on until a correct response is given. In contrast, when comprehension is tested by homework assignments, the student must wait at least a day to discover whether his understanding was correct. 
The final benefit of using $\mathrm{CAl}$ is efficiency. Preparing foreign-language students to be able to participate fully in university classes required that a large number and variety of areas be covered in a relatively short space of time. This pressure to cover not only the essentials but the finer areas of language in a short period causes practice to be telescoped to fit the demands of time. Computer assisted instruction provides the students with ample practice on their individual needs, while freeing class time to work on general areas of weakness and on the synthesis of discrete skills, if fully integrated and demonstrated to the students to be useful.

\section{PLATO}

Computer assisted instruction at Indiana University is offered through PLATO, a twenty year old ongoing macro-system with a capacity of up to two million words of memory, an unusually large capacity. The high memory capability of PLATO allows for great sophistication in two areas: lesson writing and student record keeping.

PLATO can continually keep records of contact hours and lessons completed for both an entire student group and for individual students. Indeed, most of the data an instructor or researcher might need can be obtained through PLATO's records. Some data examples might be: the time needed to complete lessons, student's incorrect answers, correct answers, all student answers, lesson scores, percentages of a group completing the lessons in a catalogue, among others. Student records can be used to remember how far a student has gone in a lesson and to start him again at the point at which he left the lesson.

The large memory capacity of PLATO is important for lesson design in that it allows multiple branching within lessons, thus coordinating lesson material with errors made by the student. This branching capacity, which permits considerable individualization of instruction, is used to advantage in many of the thousands of lessons available through PLATO, and can be used in writing one's own lesson using the relatively simple computer language, TUTOR.

In writing or locating appropriate lessons, the system-wide communications network open to instructors and authors is very helpful. Systemwide note files are maintained for various areas of interest, and instructors and authors throughout the system may communicate with each other either interacively or by leaving personal messages. The communication facilities provided by PLATO also allow extensive two-way communication between teachers and students. Students may write notes to teachers about lessons, respond to teacher notes, or ask for help from any teacher in the supervisory group who is signed on at any campus locattion. Teachers may send messages to individual students or to an entire group of students, monitor what students are doing, help students who have requested help, and answer student comments on an individual basis.

PLATO is a macro-system, which means that, within a system, one large central computer serves many student terminals. Each basic terminal consists of a screen and a key-set similar to a standard typewriter keyboard, with the addition of several function keys. Two of these function keys, 
ERASE and EDIT, deserve special mention. They allow the user to change a single word or letter without having to rewrite everything. In addition to the basic terminal, other hardware is available: slide projectors, microfiche projectors, and touch panel, the latter of which allows students to select an answer by touching the screen instead of typing all the answers. A number of audio devices including random-access audio discs and audio cassettes are being developed. Work is also being done in coupling random-access video disc technology to PLATO.

A PLATO system consists of one central computer and the terminals it serves. There are currently 14 PLATO systems world-wide. Indiana University subscribes to the CERL system, located on the ChampaignUrbana campus of the University of Illinois. There are 1300 terminals nationwide on the CERL system; Indiana University has nineteen, fifteen on the Bloomington campus. Some departments other than CELT making intensive use of PLATO at Indiana University are: business, English, journalism, math education, music, and science education. In these departments, PLATO lessons are used both for class assignments and for remedial work in areas of student deficiencies.

\section{USE OF PLATO BY THE CENTER FOR ENGLISH LANGUAGE TRAINING}

Our experience with PLATO at Indiana University has been through the Center for English Language Training. In addition to offering a master's program in applied linguistics, the Center for English Language Training runs two programs in English for non-native speakers who plan to study in the United States.

The semi-intensive program is designed for non-native speakers who have been admitted to Indiana University for academic work, but who need remedial study in one or possibly more areas of English, as determined by their scores on a diagnostic test administered to all incoming foreign students. This program offers three courses in writing, ranging from sentence-level work to writing research papers, a reading skills course, a course in expository reading, a pronunciation course, and a course in academic discussion. About one hundred students enroll for each eightweek session of these non-credit, semi-intensive courses.

The intensive program, with an average enrollment of 60-70 students, is designed for students who are in the United States to take English courses. Students are placed in one of five levels by a diagnostic placement test which is offered every eight weeks. Students in the basic and intermediate levels receive five hours of classroom instruction daily and four hours of lab per week. These three levels use an integrated textbook series which is supplemented by writing texts and lab material. The classes at the upper levels are organized in a more academic mode, using a single core text as the fpcus of classes in reading, writing, and listening/ speaking skills. These classes are designed to serve as a bridge between ESL classes and actual college classes. The students are required to be in their skills courses three hours each day, to attend writing lab three hours 
per week, and are expected to use their unscheduled time not only in preparing assignments for language class, but in readying themselves for academic work by taking classes either as auditors or for credit, and improving their English skills by using the many facilities made available by the department and the university.

The involvement of the Center for English Language Training with PLATO began in April 1979, when the students of a section of the graduate course "Methods and Materials in TESOL," were assigned to investigate the possibilities of computer-assisted instruction for teaching English to non-native speakers. The lessons which were initially found on PLATO and the capabilities of PLATO itself looked so promising that the project continued on a volunteer basis during the Summer. By the fall semester, a single PLATO student group, which had been set up with a catalogue, served as our initial PLATO curriculum. Students were allowed to select from any of these 57 lessons on their own.

Our original premise was that PLATO would serve as an optional supplement to classroom work, to be used by the students in their free time. Individual teachers were responsible for introducing their students to PLATO and assisting them in signing on, but little was done to encourage program-wide PLATO use. A few teachers assigned or suggested lessons on PLATO to their students, and one teacher took his class into the PLATO room for one hour per week, supervising the students' work and helping them when they were confused.

Even with this minimal promotion, PLATO proved popular with the students, as measured both by a questionnaire and by usage. Fifty-three students signed on PLATO in the Fall for a total of 213.2 contact hours, an average of four hours each. One student completed fifteen hours.

At the end of the fall semester, it was decided to change both the format and the philosophy of PLATO usage, for several reasons. During the fall semester of 1979, more lessons suitable to English learners had been found, and some of the original lessons were discarded because they were either too long or pedagogically unsound. Even taking into account these discarded lessons, by the end of December we had discovered in the PLATO library 225 lessons which we felt to be appropriate for our students.

If such a large number of lessons were to be used, it would mean reorganizing and subdividing the group, as each PLATO student group is limited to eighty lessons. Subdividing the group had other advantages besides allowing space for the newly found lessons: It allowed us to categorize lessons according to their level of difficulty for English learners and to use long format student records rather than short format. The long format enables students to leave a lesson that has "restart" capability and return later to the same point at which they left-a feature which is absolutely necessary to allow slower studtnts to leave PLATO and come back to finish the lesson. By subdividing the group, we could ensure long memory for those students who needed it, yet not use as many records for those who did not need it. 
The result of this reorganization was five separate student groups: beginning, intermediate, and advanced groups with long student records for students in the Intensive Englsh Program; an advanced group with short memory for students in the semi-intensive program; and a preacademic group using short memory. This last group contains typing lessons, advanced vocabulary lessons, and indices to lessons in the students' academic areas. The curriculum of the other group consists of 65 or more lessons in grammar, reading, writing, and spelling; all of which are suitable for students at the assigned level of difficulty. No student is restricted to his own group, however. All students have access to all groups through a slightly different sign-on procedure.

In reviewing student usage of PLATO during the fall semester of 1979, it was decided that a half-hour or quarter-hour introduction to PLATO was insufficient to acquaint students with their PLATO curricula and to demonstrate to them the usefulness of PLATO as a supplement to classroom work. There was relatively little usage of PLATO at the introductory levels of the intensive program because the students' schedulessix hours of class per day-allowed them very little free time for supplementary learning activities.

To overcome the time problem, it was decided that the two lowest levels should have supervised PLATO instruction for one hour each week; this hour would replace one of the four previously scheduled hours of language lab. During this hour, students could choose their own lessons within the curriculum already set up for them, but could get help and advice from the teacher.

At the other three levels in the intensive program, the PLATO usage policy was made by the teachers and level coordinators. One level assigned a specific lesson to be completed each week, while the other levels had groups of lessons assigned by individual teachers to be completed during the eight-week period. The semi-intensive English program did not change its PLATO usage policy during this period.

The change in policy in the intensive program from optional to required use of PLATO by students was the subject of considerable debate. Those who opposed the change felt that one of the advantages offered by PLATO over the other forms of instruction available was that it was learner-entered: that, given a curriculum, students could work on what they wanted, at their own place, whenever they wanted. This group also felt that since students vary in their ability to learn from different media, PLATO's teaching style would be received positively by some and negatively by others. Students should therefore not be forced to use a medium distasteful to them.

Those who felt that a change in policy was necessary pointed to the fact that a half hour or quarter hour introduction to the machine was not sufficient to get the students to feel at ease with the computer, much less to give them an idea of the wide variety of lessons available to them in their curriculum. They argued that requiring either supervised time on PLATO or a minimal number of PLATO lessons to be completed would 
achieve the goal of familiarizing students with the computer and the available curricula without imposing too great a hardship on these students for whom computer-assisted instruction was not a preferred medium of instruction.

Our experience during the spring semester has supported the change in policy made by the program. PLATO usage, both required and voluntary, increased greatly, as shown in the table below, and there has been nearly total positive feedback from the students.

PLATO usage: Spring 1980

$\begin{array}{lccc}\text { Pre-academic } & \begin{array}{c}\text { Number of Students } \\ \text { (Single Sign On) }\end{array} & \begin{array}{c}\text { Mean } \\ \text { Contact Hours }\end{array} & \begin{array}{c}202.5 \\ \text { Contact Hours }\end{array} \\ \text { Semi-Intensive program } & 33 & 93.0 & - \\ \text { Intensive Program } & \frac{78}{111} & \overline{817.8} & 3.8 \\ \quad \text { TOTAL } & \overline{813.3} & \overline{7.6}\end{array}$

\section{SURVEY OF ATTITUDES}

In order to get another measure of the value of PLATO as used in the ESL programs at Indiana University, two separate questionnaires were developed to elicit responses from both teachers and students. The student sections were separated into those from the intensive and semi-intensive programs, while teachers from both groups were measured together.

Of the 78 students questioned, only $24 \%$ had used computers previously, but $62 \%$ of the total reported that they enjoyed using PLATO, and only $9 \%$ had trouble with the system. $41 \%$ of the students found the PLATO lessons easy to understand and $92 \%$ considered them to be at least a little interesting. $80 \%$ of those questioned felt that PLATO had helped them to "learn English," and 8\% claimed that PLATO taught them even more than their English classes! While about $12 \%$ of the students reported that PLATO took too much time, and $14 \%$ said they didn't have enough time to finish some of the lessons, $46 \%$ admitted that one thing they liked most about PLATO was the fact that it let them learn at their own pace. One student went so far as to comment that PLATO is a good teacher because it is "more patient" than most of his human teachers.

Ninety percent of the students responding wanted to use PLATO again the following semester. The most popular lesson, as reported by the students, were those dealing with grammar, followed by reading lessons, including specific lessons in building reading speed. The personal and sometimes humorous qualities of PLATO were mentioned often as reasons why students enjoyed using PLATO, while other popular factors included the game element of some lessons, the chance to repeat portions of lessons until they were correct, the variety of lessons offered, and the ease of using PLATO. 
On the negative side, about $45 \%$ of the students reported that at one time or another they had not understood why an answer they had given was incorrect. Of the 78 responding students, less than $1 \%$ said that PLATO was boring, but usually there is a comparable percentage in group that complains of boredom about anything and everything. The small room used for PLATO terminals at Indiana University, along with the small number of terminals available, was often mentioned as a reason why students didn't use PLATO more.

Student suggestions for the improvement of our use of PLATO included offering a more thorough orientation to PLATO, supplying studenis with lists of the available lessons to which they could refer away from the terminal, printing out completed lessons so that students could take them home and study their mistakes, and arranging more coordination with classes.

The eight teachers who had used PLATO all agreed that PLATO had helped their students. Four of the teachers responding had never used it, but two said they definitely planned to use it in the future, one with upper level students and one with lower level students.

Grammar and vocabulary lessons were perceived by the teachers as the most useful for their students, while reading and writing lessons came next. Specific good qualities of PLATO mentioned by teachers included the element of individualization, the ability to handle discrete point problems, and the positive reinforcement offered to students when correct answers were produced. The immediate feedback, the personalized approach, and the variety of lessons also earned praise from teachers.

Teachers joined students in criticizing the physical setting of terminals and the relatively small number of readily available terminals. Teacher suggestions included assigning PLATO monitors to help students when they had trouble with the lessons and generating more teacher enthuiasm by organizing training sessions in which teachers would not only be thoroughly introduced to the capabilities of PLATO and the lessons available on it, but also learn how to integrate PLATO into the actual teaching curriculum.

From teachers who had instructed their students to use PLATO or who had monitored students came the following anecdotal reports.

One student in the lowest level of intensive English simply could not keep up in his classwork at first. Due to the lack of work and concentration, he simply could not make connections in class, and thus was not progressing. When he got to PLATO, however, he "turned on," and was not only interested, but excited. He was the quickest of the group to understand directions and to progress in his use of PLATO. His teacher reported that his drastic change of attitude and greater achievemen convinced her of PLATO's value.

Another student, also at a low level, made a remark that is hard to forget: "I have found the perfect teacher. You say, 'Be quiet!' and 'No!' PLATO says 'I love you Milud.' 'I admire your brains.' " 
Yet another student spent so many hours working on PLATO lessons during the semester that one of his teachers reported that he "had gone berserk." He comple:ed over 50 hours of work during the semester, while even more of his time was spent doing lessons in the pre-academic catalogue using a different type of sign-on.

The pre-academic group proved popular with many of the more advanced students, who used it for more than 200 hours during the semester. Quite a number of students remarked on their questionnaires that they had appreciated being able to do lessons outside of English, in such areas as calculus, computer science, journalism, music, and typing. One student claimed that she became interested in the typing lessons because they would help her use PLATO more easily!

\section{SUGGESTIONS FOR USING CAI IN A LANGUAGE PROGRAM}

While our experience using PLATO to supplement regular language classes and language lab has been positive, as judged both by usage and by student and teacher response, in the past year we have learned much about using PLATO effectively, and would like to share our suggestions, based on what we have done, should have done, and plan to do.

Organization: communication and cooperation are necessary from the very beginning. If PLATO or other CAI systems are available at your location, it is necessary to talk with other users and with the site director about what facilities are available and how schedules for your students can be arranged. The number of terminals available and the assignment of terminal time will be a crucial factor in deciding whether CAl will be used as an integral part of a program or as a supplement. Talking to other users, especially users in the language arts, will provide much insight into the strengths and weaknesses of the system, ideas on how to use the facilities, and information about available lessons.

If $\mathrm{CAl}$ is not currently available, but the possibility of investing in a system is being investigated, it is absolutely essential that language departments get together to have some input into the decision-making process. If CAI facilities are to be provided by a university, it is only fair that all departments be able to benefit equally from them. Language departments should make sure that the systems being considered are capable of handling sophisticated language lessons, which, because of the complexity of language itself, require very large memory capability. Potential users should also examine the lessons available on the system, unless they plan to write quantities of lessons themselves which is usually a very long-range goal.

After having ascertained the availability of CAl, you will have to decide how to use it initially in the program. It may be used as a voluntary resource, much as a library is used; it may be used as a recommended resource, as recommended readings are used; it may be required for a course or a section of a course; or, in extreme cases when no trained language teachers are available, it may be set up as the whole curriculum. 
When the initial goals have been set, we strongly recommend designating a coordinating committee to act as a communications channel both within the program and with other users, whether on-campus or within the nationwide network. This committee would be responsible for establishing policy, setting up and coordinating the CAI curriculum, and evaluating the effectiveness of the chosen curriculum through feedback from teachers and students.

Curriculum: The first duty of the committee would be to locate lessons appropriate to the content of the program. There are over 300 lessons on the PLATO system which could be incorporated into an English language program. These lessons, like the lessons available in other languages, vary in subject matter, quality, length, sophistication, and memory requirements. The committee should go through the available lessons and make a master list of lessons they feel to be appropriate.

This master list may form the basis of the initial curriculum, but need not be the final one. Lesson evaluation should be an ongoing process, involving monitors, students, and teachers. The ultimate proof of the value of a lesson seems to be in the student response.

We feel that it is advisable for someone to supervise students while they are working on lessons. Monitors are important to lesson evaluation because they observe the students working on the lessons, and thus can tell which lessons are appreciated and which are not. When establishing PLATO or another CAI system as part of a program, one must remember that native speakers or even experienced language teachers are not always good judges of which lessons work best. In choosing lessons for our catalogue, we were tempted to discard many possibilities as overly repetitive and boring. We discovered, much to our surprise, that some of these lessons were appreciated by our students for their thoroughness. The students also found some lessons to be far more difficult than we. had thought them to be, and occasionally were extremely frustrated by devices intended to enliven lessons.

As new lessons become available on PLATO, and as the curriculum of the program itself changes, the evaluation of CAI lessons by monitors, students, teachers, and the coordinating committee should continue to ensure the best possible fit between the needs of the students and the supplementary materials available.

There are many ways of organizing lessons into a PLATO curriculum. You may find it desirable to subdivide the curriculum according to levels of student ability, as we have done, or it might prove more advantageous to subdivide it by skills. Another possibility is for lessons from the curriculum to be assigned by the teachers of sections. A new student routing system on PLATO, The Indiana Routing System (TIRS), allows lessons to be assigned to an entire group, to a section of a group, or to individual students. The instructors have the ability to make these lessons required, optional, or tested. Tested topics give both a pretest and a post-test designed by the instructors, who also set the criteria 
for passing. If a student passes the pre-test, he does not have to do the lessons on that topic, although he may work through them if he wishes. This routing system, which we plan to use for grammar lessons, allows students to work at a level commensurate with their abilities, and allows individual teachers much more input into the system.

Teacher Workshops: One of the most important duties of the coordinating committee is to keep teachers informed and to promote enthusiasm among them. A PLATO workshop scheduled during teacher orientation would be an ideal way to familiarize new teachers with the computer and the curriculum, to acquaint old teachers with new lessons and other changes, and to air out problems that have been encountered. Having this workshop before classes begin would ensure that the teachers would not be depriving students of time at the terminals nor would the teachers themselves be deprived of time needed for class preparation.

At the workshop, the coordinators should distribute written instructions about using the system and a written list either of the entire PLATO curriculum to be used or of the lessons relevant to each teacher's assignments. Written instructions are needed because users quickly forget how to sign on after a single demonstration. One of the most daunting aspects of PLATO to the novice is the absence of "hard copy." One seems to feel much more secure looking up information on pieces of paper filed away personally than accessing the same information on a screen with the push of a button, even if it is faster and often more accurate. Giving written handouts to teachers relieves some of their anxiety about computers, and also gives them something to refer to when they are preparing lesson plans away from the terminal.

As part of the workshop, the teachers could pair off and work through sample lessons appropriate to their teaching assignments. As we have many more teachers than terminals, pairing-off is necessary if all the teachers are to become familiar with PLATO within a few hours. Working in pairs or in groups has other advantages. It allows people with CAI knowledge to help more effectively those who have none; it allows role-playing with one teacher acting as a student and another as monitor, and it encourages all of the teachers to get acquainted with the computer, even those who privately feel that they are too old to learn new tricks.

As the program continues, and more and more teachers become familiar with the curriculum, these workshops could provide much feedback about the kinds of lessons the teachers feel are needed and the problems with existing lessons. At this point some teachers might want to become authors and write lessons tailor-made for the needs of their students.

Helping Students: Students, like teachers, should be given written handouts on how to sign on, and also if possible, written lists of the lessons available. Although, in our experience, students are less apt to be afraid of the computer than teachers, they are equally apt to forget how to sign on after a single demonstration. 
As stated before, we feel that it is wise to have a monitor in the terminal room with the students. The students can encounter difficulty on three levels: with the computer, with the lesson, and with the language. If the difficulty is with the system, the monitor can explain the difficulty to the student, relieving of the feeling that somehow it was his fault. If the difficulty is with a lesson, the monitor can show the student how to leave a note about the problem, or can write the note himself. These notes are acted upon by the coordinating committee, which tries the lesson, and if it is indeed defective, removes it from the curriculum, while notifying the lesson author of the problem so that it can be corrected. If the problem is with the language, whether with a word or construction the student has forgotten or has never met, the monitor can explain the meaning to the student. When a lesson is beyond the ability of a student, he can suggest another one, and leave a note to indicate that the lesson is too difficult for the level.

Although feedback about lessons comes primarily through the monitor, especially at the lower levels, all students should be taught how to use the channels of communication available through PLATO, particularly if they are to be working on their own, outside of regularly scheduled hours. Students should be encouraged to ask for help when they need it and also to leave notes about the assignments, the lessons, or themselves. The more they experience themselves in the language they are learning, the better.

Evaluation: Evaluation should be established as an integral part of the PLATO program from the very outset. When people are interacting with machines, it is vital that some means be provided to determine the success of the interaction. Evaluation is needed not only to satisfy the instructor's curiosity and to suggest areas of improvement, but also to justify the use of CAI.

Our evaluation has concentrated on three areas: tabulation of contact hours, questionnaires soliciting feedback from students and instructors, and unsolicited comments from students, teachers, and monitors. From these sources we have gathered objective data on specific lessons, which we have used to improve our curriculum; and subjective data on how our students and teachers feel about our use of PLATO as a supplement to classroom work, which has convinced us that we should continue to use PLATO in the future. 


\section{DIRECTIONS IN COMPUTER ASSISTED INSTRUCTION}

As businesses and institutions expand their use of computers in employee training, there are promises of technological developments which will increase the capabilities of CAl, yet make it more economical due to wider use.

Among the technical innovations being developed on PLATO which could add desirable dimensions to using PLATO for language teaching are audio devices, random-access video discs, and speech synthesizers capable of text-to-speech output.

Using a macro-computer such as PLATO will become more economical for teaching large numbers of students when a cluster system is developed. The cluster system will combine the advantages of the micro-computer with the advantages of a central delivery system, keeping the large memory and data basic of the latter, but combining it with the economy of the former. It will use stand-alone micro-computer based terminals which get their lessons from a 'cluster host,' a computer connected to the central system. The cluster host will be used for record keeping, as well as for accessing and processing lessons for the micro-computers.

Like every market, the market in computers is responsive to demand. The field of language teaching should not be deprived of the benefits of the computer as an instructional device. As the field of computer assisted instruction develops, language teachers should develop with it, making their unique needs known so that as the field grows, it will continue to serve our needs.

Anne l. Merkel

English Language and Multicultural Institute

795 Livermore Street

Yellor Springs, $\mathrm{OH} 45387$

(513) 767-7331

Ann Burke

Marlin Howard

Judy Leidy

Center for English Language Training Program

School of Education

Indiana University

Bloomington, IN 47401

(812) $337-4332$ 